\title{
How can climate change and engineered water conveyance affect sediment dynamics in the San Francisco Bay-Delta system?
}

\author{
Fernanda Achete $^{1}$ • Mick van der Wegen ${ }^{1,2,3}$. \\ Jan Adriaan Roelvink ${ }^{1,2,4} \cdot$ Bruce Jaffe $^{5}$
}

Received: 22 March 2016/Accepted: 16 March 2017 / Published online: 24 April 2017

(C) The Author(s) 2017. This article is an open access publication

\begin{abstract}
Suspended sediment concentration is an important estuarine health indicator. Estuarine ecosystems rely on the maintenance of habitat conditions, which are changing due to direct human impact and climate change. This study aims to evaluate the impact of climate change relative to engineering measures on estuarine fine sediment dynamics and sediment budgets. We use the highly engineered San Francisco Bay-Delta system as a case study. We apply a process-based modeling approach (Delft3D-FM) to assess the changes in hydrodynamics and sediment dynamics resulting from climate change and engineering scenarios. The scenarios consider a direct human impact (shift in water pumping location), climate change (sea level rise and suspended sediment concentration decrease), and abrupt disasters (island flooding, possibly as the results of an earthquake). Levee failure has the largest impact on the hydrodynamics of the system. Reduction in sediment input from the watershed has the greatest impact on turbidity levels, which are key to primary production and define habitat conditions for endemic species. Sea level rise leads to more sediment suspension and a net sediment export if little room for accommodation is left in the system due to continuous engineering works. Mitigation measures like levee reinforcement are effective for addressing direct human impacts, but less effective for a persistent, widespread, and increasing threat like sea level rise. Progressive adaptive mitigation measures to the changes in sediment and flow dynamics
\end{abstract}

Electronic supplementary material The online version of this article (doi:10.1007/s10584-017-1954-8) contains supplementary material, which is available to authorized users.

Fernanda Achete

fernandaachete@gmail.com

1 Department of Coastal Engineering and Port Development, UNESCO-IHE, PO Box 3015, 2601

DA Delft, The Netherlands

2 Deltares, Boussinesqweg 1, P.O. Box 177, 2629 HV Delft, The Netherlands

3 Deltares, P.O. Box 177, 2600 MH Delft, The Netherlands

4 Technical University Delft, Stevinweg 1, 2628 CN Delft, The Netherlands

5 U.S. Geological Survey Center, 400 Natural Bridges Drive, Santa Cruz, CA 95060, USA 
resulting from sea level rise may be a more effective strategy. Our approach shows that a validated process-based model is a useful tool to address long-term (decades to centuries) changes in sediment dynamics in highly engineered estuarine systems. In addition, our modeling approach provides a useful basis for long-term, process-based studies addressing ecosystem dynamics and health.

\section{Introduction}

In estuaries, fine sediments transported from the watershed determine turbidity levels to a high degree. High turbidity levels attenuate light penetration in the water column limiting primary production, define habitat conditions for endemic species (Brown et al. 2013), nourish marshes and tidal flats, and carry nutrients and contaminants to intertidal and coastal areas. Natural and anthropogenic changes in environmental conditions modify the sediment dynamics, turbidity levels, and the system's resilience to future impacts (Hestir et al. 2013; Schoellhamer 2011; Winterwerp and Wang 2013).

The human impact on sediment load is similar for several estuaries worldwide. Initially, an increase in sediment load due to deforestation, changes in land use, or mining activities is followed by a sharp decrease in sediment load resulting from reservoir construction and riverbank reinforcement (Syvitski et al. 2005; Walling and Fang 2003; Whitney et al. 2014). Examples of this pattern of changes in sediment load are the San Francisco Bay-Delta (Barnard et al. 2013), the Ebro (Guillén and Palanques 1997), and the Yangtze River Delta (Wang et al. 2015). Human activities such as channel deepening (van Maren et al. 2015; Winterwerp and Wang 2013), land reclamation, and water deviation for agriculture and human consumption further impact the sediment dynamics of estuaries (Scavia et al. 2002).

Since the beginning of the Holocene, sea level rise (SLR) has had a large influence on estuarine sediment dynamics (Roy 1994; Borrego et al. 1993). Current SLR predictions for the State of California range from 0.42 to $1.67 \mathrm{~m}$ by 2100 (NRC 2012). Estuarine salt marsh vegetation can be resilient to SLR as long as sediment supply is high enough to keep with the rate of SLR (Fagherazzi et al. 2012; Reed 2002).

To maintain prevailing habitat conditions, estuaries need to trap sediment when SLR. Reservoir construction prevents sediment from the watershed entering the estuarine domain. In addition, episodic river floods that once were responsible for resetting the system and transporting large amounts of sediments seaward are increasingly rare due to flood control barriers and water diversions. For the Sacramento-San Joaquin Delta (Delta), this has led to a depletion of the downstream sediment pool and a change from transport limited suspended sediment concentration (SSC) to supply limited SSC (Schoellhamer 2011; Schoellhamer et al. 2013).

The impact of SLR relative to shorter-term engineering measures is an important discussion in estuaries dynamics (Dettinger et al. 2016). In this work, we evaluate the possible impact of direct human disturbance (e.g., water diversion operations, levee failure) and climatic change on estuarine sediment dynamics with a focus on the highly engineered estuary of the San Francisco Bay-Delta system. We selected the Bay-Delta system because it is data-rich, which facilitates model calibration and validation. A twodimensional (2DH), vertically aggregated, process-based, numerical model (Delft3D FM) is used to describe sediment dynamics and simulate the sediment budget and patterns in SSC, and turbidity levels. These data are translated into turbidity levels in order to assess the impacts on habitat conditions. 


\section{Study area}

San Francisco Bay and the Delta constitute the San Francisco estuary (Fig. 1). The estuary covers an area of $2900 \mathrm{~km}^{2}$ and collects $40 \%$ of the total fresh water flow of California, making it the largest estuary on the US west coast (Jassby et al. 1993). It hosts marshes and several endemic species of fishes. It is densely populated, and has industries and intense agribusiness. The competing demands result in a highly managed estuary.

Tides propagate from Golden Gate into the Delta up to Sacramento. The boundary between the Bay and the Delta is near Chipps and Mallard Island. Mallard Island experiences mixed diurnal and semidiurnal tides that range from about 0.6 to $1.8 \mathrm{~m}$ (neap-spring tide). During dry season, tidal oscillation is observed in the Sacramento River up to the Freeport station and in the San Joaquin River up to the Vernalis station.

Located landward of San Francisco Bay, the Delta is an inland, natural and man-made, channel network formed by the junction of two main tributaries, the Sacramento River and the San Joaquin River (Fig. 1). These rivers contribute 90 and 9\%, respectively, of the total runoff.

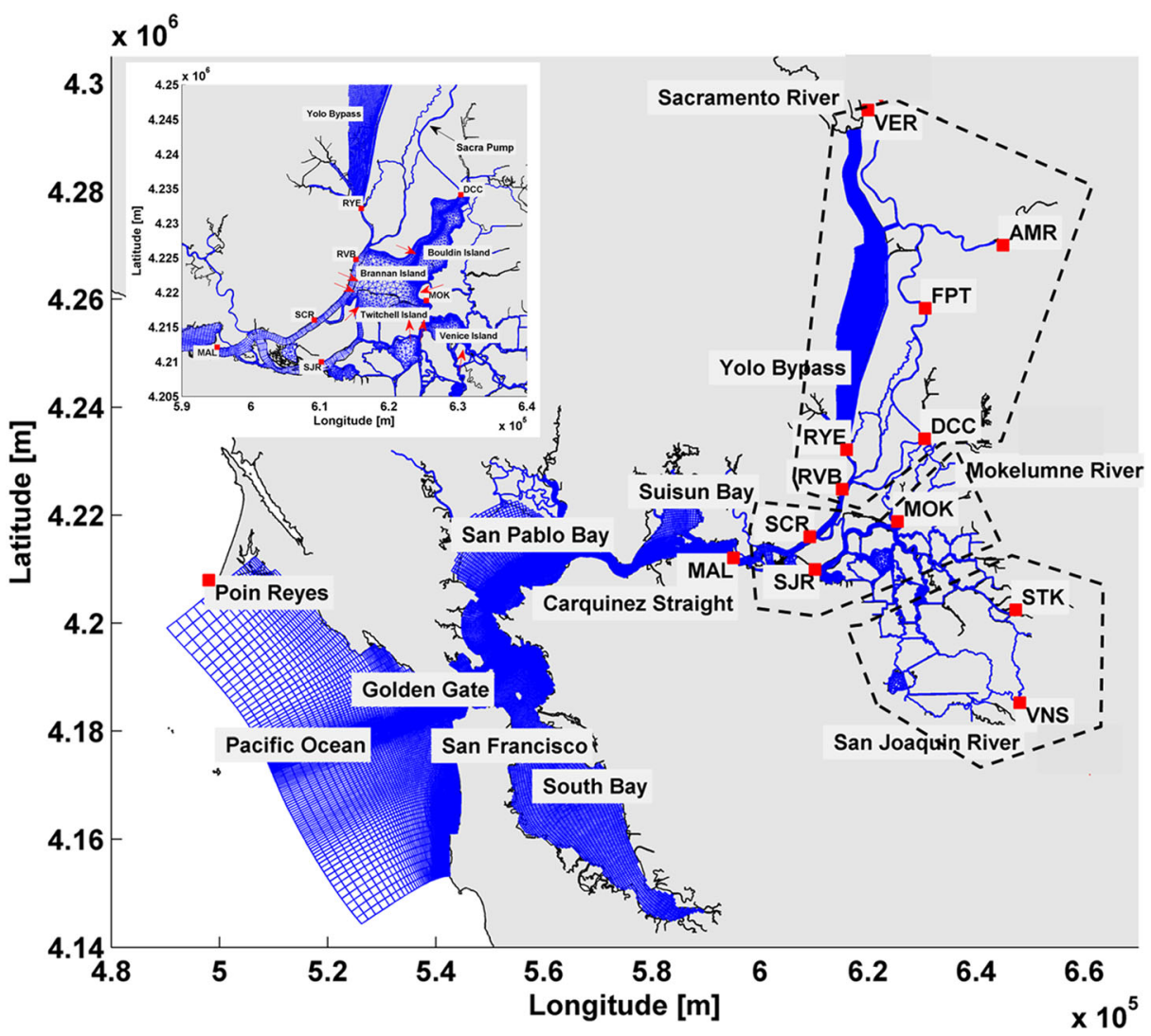

Fig. 1 Map showing San Francisco Estuary, Bay, and Delta. In blue is the grid. The observation stations are represented by the red squares. The Delta areas (North, Central, and South) are delimited by the dashed polygons. Upper-left inset: Modified grid that includes the flooded islands of Twitchell, Brannan, Bouldin, and Venice. Levee breaches are indicated by the red arrows. The black arrow indicates the location of the pumping in Sacramento River in the SacraP scenario 
During winter or early spring, peak river discharge lasts several days to weeks and delivers the majority of fresh water to the Delta. The Delta discharge varies between $50-150 \mathrm{~m}^{3} \mathrm{~s}^{-1}$ during summer and $800-4000 \mathrm{~m}^{3} \mathrm{~s}^{-1}$ during the spring/winter (Kimmerer 2004). Apart from the intrayearly seasonality, the Delta experiences inter-annual variability with wetter (e.g., 2011) and drier years (e.g., 2013).

During the wet season, the Sacramento River pulse increases SSC and exports sediment towards the Bay, affecting biota behavior (Ganju and Schoellhamer 2006; McKee et al. 2006, 2013). On average, the Delta stores roughly two-thirds of the sediment input for both wet and dry years (Wright and Schoellhamer 2005; Marineau and Wright 2014; Achete et al. 2015).

The Delta includes engineered channels and several temporary barriers constructed to improve water quality and fish habitat. The most important engineered channel is the Delta Cross Channel (DCC, Fig. 1), which is one of the three connections between the Sacramento River and the Central and South Delta (Achete et al. 2015). Water diversions for agriculture and human use are done via a pumping station located in the South Delta. In an average year, $200 \mathrm{~m}^{3} \mathrm{~s}^{-1}$ of water is pumped to Southern California (Kimmerer 2004). The pumping rate is designed to keep the 2 psu (salinity) line landwards of Chipps Island to avoid salinity intrusion into the Delta.

Over the last three centuries, human activities have had a significant effect on San Francisco estuary. Beginning in the 1850s, the Sacramento River watershed experienced 35 years of hydraulic mining, which remobilized in total $1.1 \times 10^{9} \mathrm{~m}^{3}$ of sediment. The sediment was transported from rivers in the foothills all the way to the Bay. The very high sediment loads shoaled channels, nourished tidal flats and marshes, and shoaled northern San Francisco Bay up to $5 \mathrm{~m}$ in places during a 30-year period (Jaffe et al. 2007; Wright and Schoellhamer 2004; Barnard et al. 2013).

After a California Supreme Court decision in 1884 that prohibited discharge of mine tailings to rivers, which effectively stopped hydraulic mining, major civil works were carried out in the Delta and watershed. Levee construction around Delta marshes created "islands" for agricultural purposes and increased hydraulic conveyance. Water diversion and upstream dams reduced sediment input to the Delta and Bay (Delta Atlas 1995; Wright and Schoellhamer 2004, Beagle et al. 2015).

\section{Methodology}

\subsection{Model description}

In this study, we apply the model developed, calibrated, and validated by Achete et al. (2015) to explore the impacts of disturbances such as pumping activities, levee breaching, and sea level rise. We present a detailed analysis for three representative water years (WYs). The WY is defined from 1 October to 30 September of the next year to keep the entire wet season in one hydrological year. Different scenarios are run for WYs that are wet, below normal, and dry (Fig. 2).

The Delft3D Flexible Mesh (Delft3D FM) is a hydrodynamic and morphodynamic unstructured mesh, process-based model, based on finite volume approach (Kernkamp et al. 2010; Deltares 2014). Delft3D FM allows for straightforward coupling of its hydrodynamic modules with a water-quality model, Delft3D-WAQ (DELWAQ) (Achete et al. 2015).

DELWAQ solves the advection-diffusion-reaction equation and the KronePartheniades for cohesive sediment (Ariathurai and Arulanandan 1978; Krone 1962). 

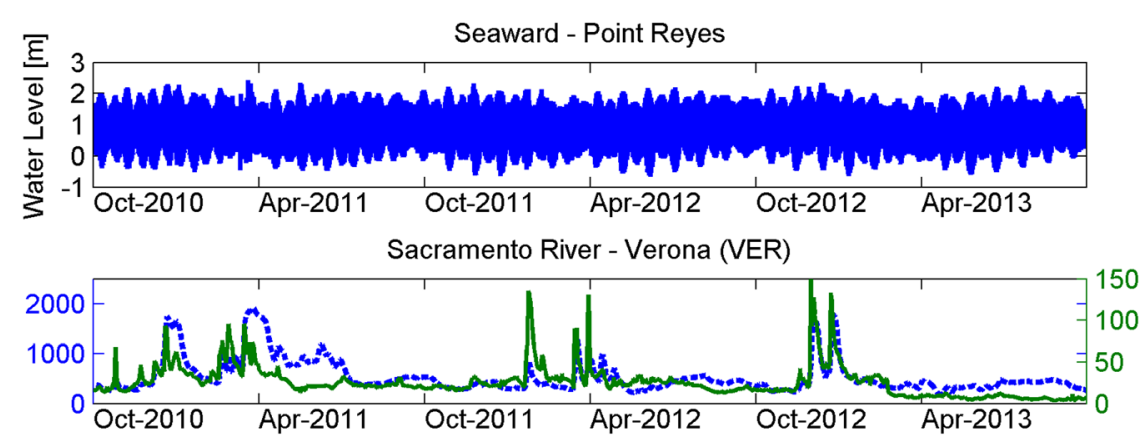

American River - (AMR)
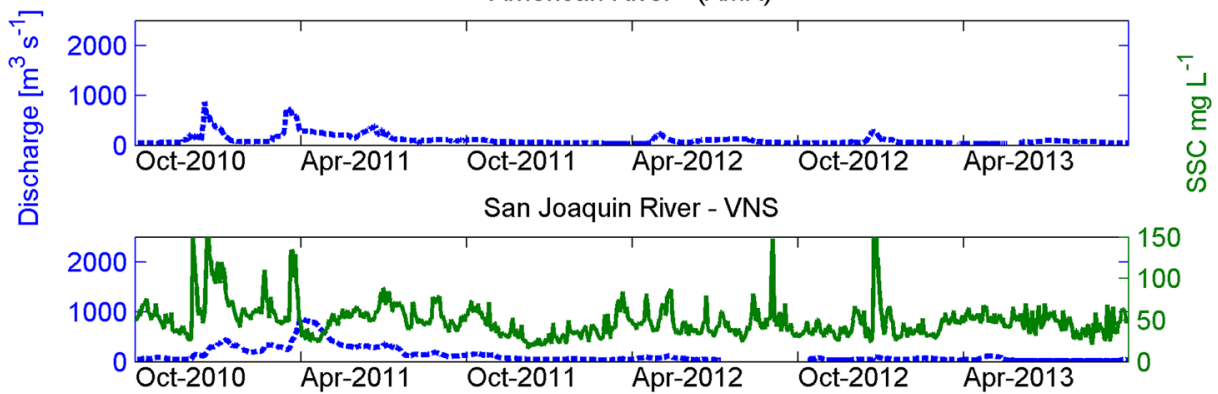

Mokelumne River - Near Wood Bridge (MOKwb)

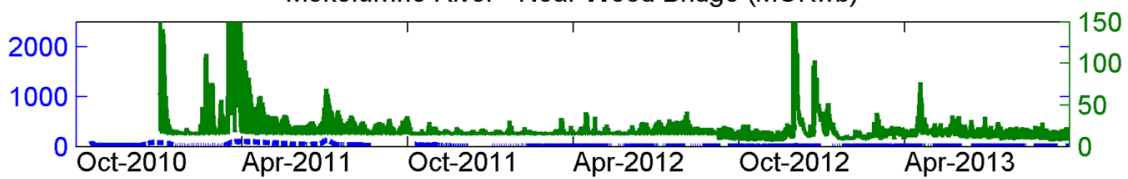

Fig. 2 Input boundary condition for the three WYs, wet (2011), dry (2013), and below normal (2012). Top panel (a) water level at seaward boundary (Point Reyes), the following four panels show discharge as a dashed blue line and SSC as a solid green line for Sacramento River at Verona (b), American River (c), Mokelumne River near Wood Bridge (d), and San Joaquin River at Vernalis (e), respectively. There are no known observations of sediment concentrations for AMR

We applied the 2D horizontal, vertically aggregated model that does not account for vertical variations in water flow. Major salt-fresh water interactions occur in the Bay outside the Delta (Kimmerer 2004).

The model grid comprises the full Bay and Delta with resolution ranging from 500 to $20 \mathrm{~m}$ (Fig. 1). The time step in Delft3D FM is calculated online based on a maximum Courant flow criterion of 0.7 being on average $15 \mathrm{~s}$. The DELWAQ time step is $5 \mathrm{~min}$. Both hydrodynamics and sediment calibration parameter settings were established previously by Achete et al. (2015) and applied for all scenarios (http://www.d3d-baydelta.org).

\subsection{Scenarios}

The Bay-Delta system has an extensive monitoring network, providing in situ observations for model boundary forcing, validation, and calibration. The base-case reflects the current conditions and is used as the standard run for comparison with scenarios of direct human impact (shift in water pumping location), climate change (SLR and SSC decrease), and abrupt disasters (island flooding, possibly as the results of an earthquake). 


\subsubsection{Base-case scenario}

The seaward boundary water level is derived from hourly time-series at the Point Reyes station (tidesandcurrents.noaa.gov/). The initial water level is $1.5 \mathrm{~m}$, and the model spin-up time is less than a week for the 2D simulations. Landward, hourly water discharge and SSC are defined at locations on the main Delta tributaries (Fig. 1). Landward boundaries are located on the Sacramento River at Verona and on the American River, for the South Delta on the San Joaquin River at Vernalis, and for the East Delta on the Mokelumne River at Woodbridge (http://sfbay.wr. usgs.gov) (Fig. 2). In the model, two pumps are implemented in the South Delta at Tracy and Clifton Court. The pumps are defined as negative discharge and will transport sediment in amounts determined by local SSC levels and the intensity of pumping. The hydrodynamic model includes wind as prescribed by the model of Ludwig and Sinton (2000).

At Vernalis and Mokelumne at Woodbridge, SSC in situ observations are available and applied as a boundary condition. At Verona, only the median turbidity in ntu units is available. The turbidity values were converted to SSC by the rating curve (personal communication, USGS Sacramento) $\mathrm{SSC}=\exp \left(0.789^{*} \log 10\right.$ (turb) + 0.567) (Fig. 2). At American River, SSC was defined as a constant concentration of $10 \mathrm{mg} \mathrm{L}^{-1}$.

Over the model domain, the initial SSC was set at $20 \mathrm{mg} \mathrm{L}^{-1}$, which is typical for the dry season. The model is initialized with no sediment available in the bed following the discussion in Achete et al. (2015) and the findings of Schoellhamer (2011) of a depleted sediment pool.

\subsubsection{Pumping scenario at Sacramento River}

The pumping boundaries are shifted from the South Delta to the Sacramento River upstream from DCC following the BDCP project. The project A4 (http://baydeltaconservationplan. com/Home.aspx) considers the construction of a tunnel north of DCC until the Southern Delta pumps. The pumping rate is defined depending on Sacramento River discharge (supplementary material).

\subsubsection{Flooded island scenario}

All the boundaries are kept from the base-case. A flooded island is formerly leveed land where a levee breaches leading to formation of a "lake." This scenario is relevant since the Delta is located in a seismically active region. A strong earthquake could lead to massive levee failures. The model grid is extended covering Brannan Island, Twitchell Island, and Bouldin and Venice Island (Fig. 1). The levees to be breached are defined based on highest probability of flooding in the past and future years (DWR, risk report 2009), and overtopping probability (Brooks et al. 2012). We stress that this is a hypothetical case used as a preliminary assessment. The flooded island scenario includes fetch limited wind-waves.

\subsubsection{Sea level rise scenario at 2100}

The SLR scenario is defined by increasing water levels at the seaward boundary by $1.67 \mathrm{~m}$. This value is based on the guideline report by California Ocean Protection Council and is considered as a maximum rise after 100 years (NCR 2012).

The landward boundaries and grid extend were maintained so that extra flooding of land in the model domain was included. Although river discharge scenarios suggest a more 
concentrated wet season earlier snow melt and a larger rain to snow rate (Knowles and Cayan 2002), the average total yearly river hydrograph would keep the same volume. In this case, selecting a future hydrograph and its correlated sediment rating curve would lead to more uncertainty than maintaining the current conditions as boundary conditions (Warrick 2014).

We also created a scenario representing both SLR and decrease of SSC load. Recent data show that the rate of decrease is most probably about $0.8 \%$ per year (personal communication, Schoellhamer). A rate of $0.8 \%$ per year in 78 years accounts for a $62 \%$ decrease by 2100 . This scenario applies the same boundary conditions as in the SLR scenario, but the SSC is only $38 \%$ of the original. Finally, we included an additional scenario including all direct human impacts and climate change impacts.

We divided the Delta into North, Central, and South regions to facilitate the analysis. The North Delta is represented by the cross-sections Rio Vista and Freeport. The South Delta is represented by Stockton and Vernalis. The Central Delta is represented by San Joaquin and Mokelumne. The Delta output is at Mallard (Fig. 1).

\section{Results}

\subsection{Base-case}

In the base-case, the mean water level increases towards Freeport and Vernalis, while the tidal wave amplitude is attenuated by bottom friction and river discharge (Fig. 3). The high river peak discharge events appear as a step increase in the cumulative suspended sediment discharge towards the Bay (Fig. 4), and it is possible to track them from Freeport downstream to Mallard Island.

The isoline of $35 \mathrm{mg} \mathrm{L}^{-1}$ corresponds to a turbidity of $18 \mathrm{ntu}$. This is a minimum habitat threshold for Delta smelt, which is an important Delta ecosystem indicator species (Brown et al. 2013). The isoline migration landward indicates deterioration of habitat conditions while seaward migration indicates improvement. During the wet year (2011), the $35-\mathrm{mg}-\mathrm{L}^{-1}$ isoline is $12 \mathrm{~km}$ more seaward than in the below normal of 2012, while for the dry year of 2013, the isoline is $20 \mathrm{~km}$ more landward.

The sediment budget indicates the difference between the amount of sediment entering the Delta at Freeport and at Vernalis and the amount leaving at Mallard Island and through the pumps, thus indicating the Delta sediment storage $(\Delta S)$. The trapping efficiency $(\Psi)$ is the percentage of sediment input flux deposited (Fig. 5). In WY 2011, a wet year, $\sim 1500 \mathrm{kt}$ of sediment entered the Delta and $\sim 500 \mathrm{kt}$ was exported resulting in a $\Psi$ of about $60 \%$. During the dry year of $2013, \Psi$ is $70 \%$, which is $10 \%$ greater than that in the wet year.

\subsection{Comparison of scenarios}

\subsubsection{Mean water level and tidal prism}

The SLR scenario shows a higher mean water level decreasing bottom friction impact and further penetration of the tidal wave into the Delta. The flooded island scenario increases the tidal prism leading to higher velocities in the channels and more tidal energy dissipation (Fig. 3). The flooded island stores flood water that is not used for further propagation 

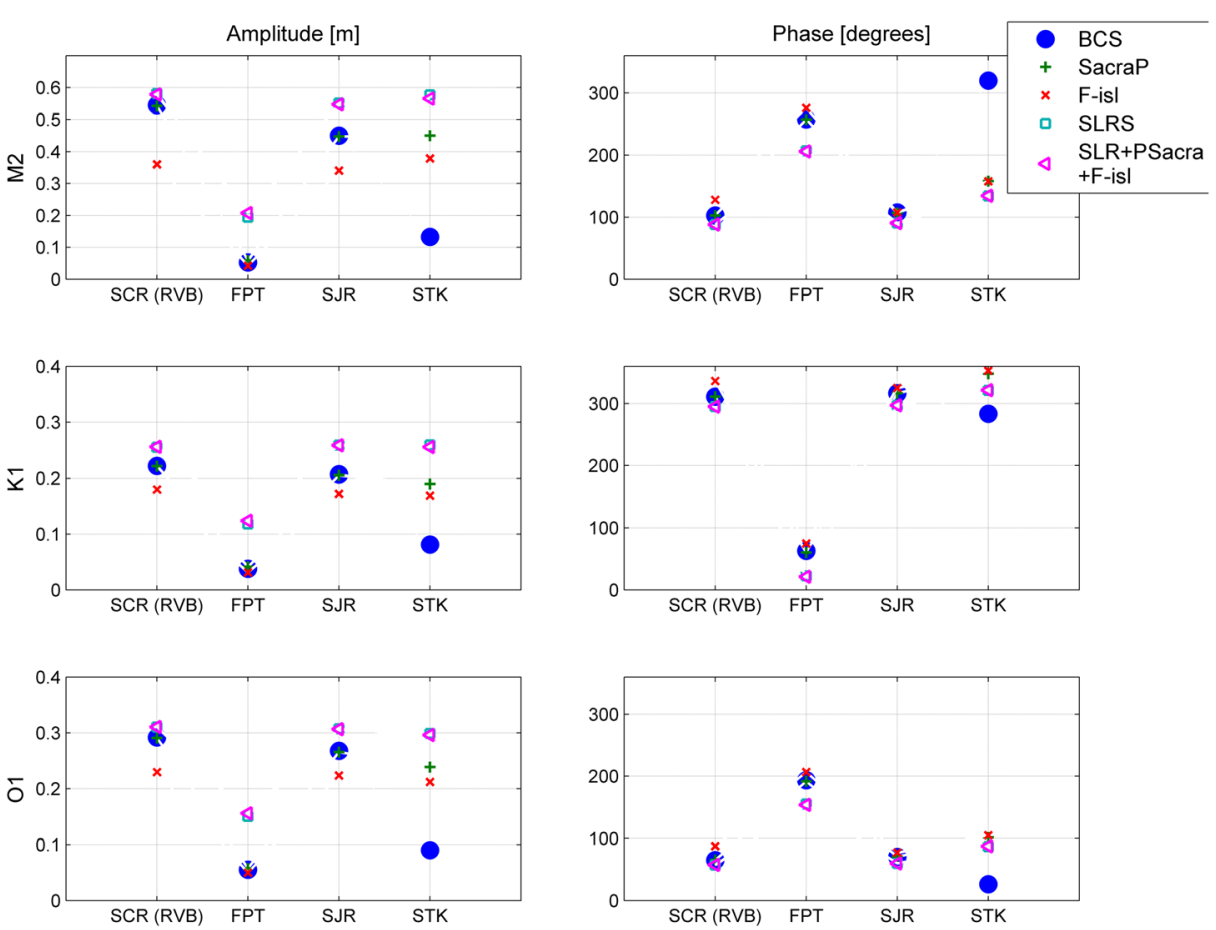

Fig. 3 Water level amplitude at Rio Vista and Freeport, SJR, and Vernalis (markers) for all the scenarios, showing the difference in tidal attenuation for amplitude and phase. Base-case scenario (BCS), pumping scenario at Sacramento River (SacraP), flooded island scenario (F-isl), SLR scenario at 2100 (SLRS)

upstream. The changes in friction lead to differences in tidal phasing. In the SLR scenario, the tidal wave propagates faster and the phase difference with the sea boundary is smaller than the base-case, while in the flooded island scenario, the tidal wave propagates slower increasing the phase difference (Fig. 3).

The flooded island scenario shows an increase in tidal prism of $20 \%$ (due to the flooded island) compared to current conditions while the SLR scenario shows a tidal prism increase of less than 5\%. The increase in tidal prism is associated with higher velocities (Fig. 3) and slightly changes in net discharge.

\subsubsection{Secondary circulation}

The flooded island scenario favors a secondary circulation that slightly increases the tidal residual discharge in the Central Delta. The secondary circulation results from water level phase differences, inducing a circulation around and inside the islands. The increase in mean water level (SLR scenario) decreases bottom friction in the entire Bay-Delta system. In this scenario, the tidal wave amplitude is larger for all the tidal constituents and propagates faster (Fig. 3). At Freeport, the tidal amplitude for the SLR scenario is $\sim 0.5 \mathrm{~m}$ while in the base-case, it is $\sim 0.05 \mathrm{~m}$ (Fig. 3). In the SLR scenario, the tidal amplitude in Freeport and Stockton is ten times larger compared to that in the base-case. SLR increases flow velocities and leads to higher mean SSC in the Delta pushing the 35$\mathrm{mg}-\mathrm{L}^{-1}$ isoline $10 \mathrm{~km}$ seawards (Fig. 6). 


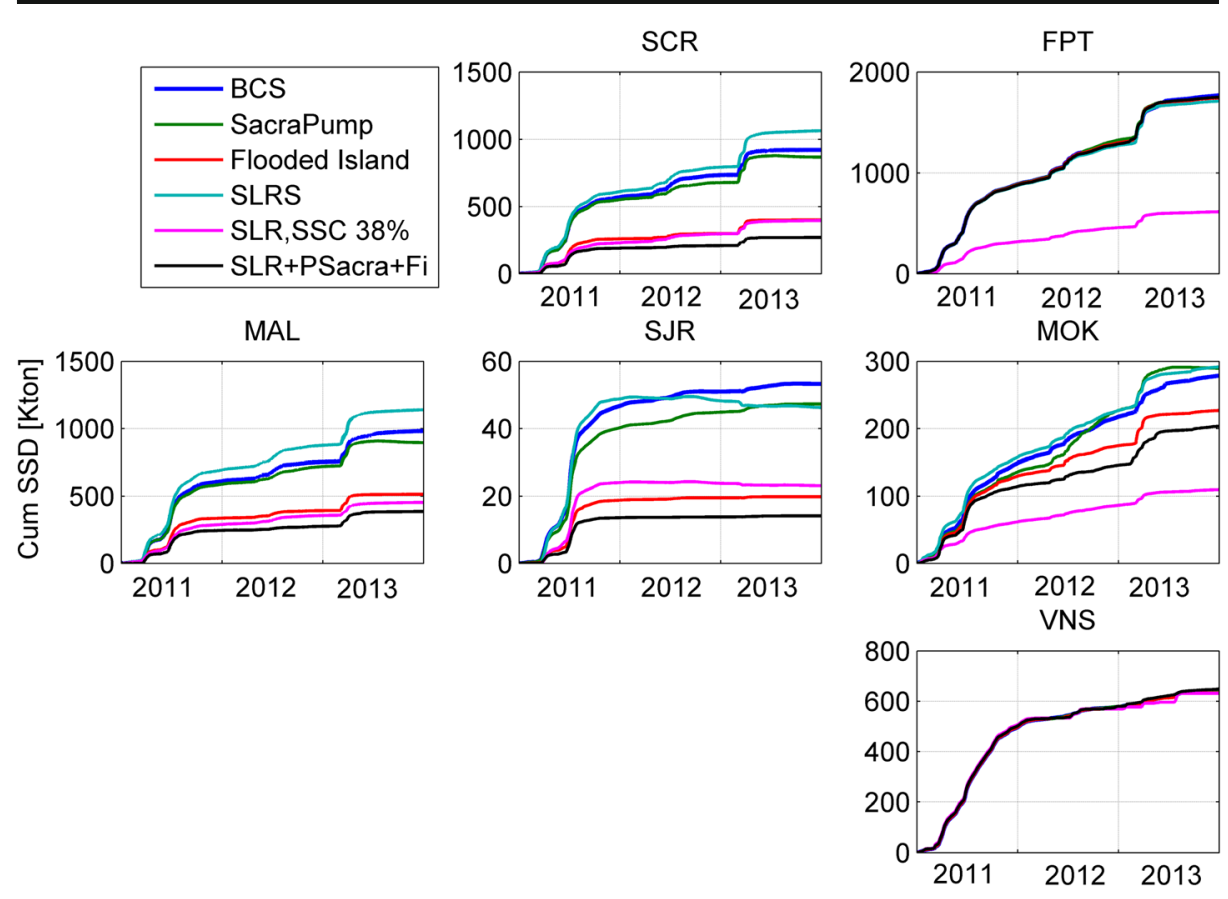

Fig. 4 Cumulative suspended sediment discharge towards the Bay following the Sacramento River at Freeport (FPT), Rio Vista (SCR), and following the San Joaquin River, Vernalis (VNS), Mokelumne (MOK), and SJR. Mallard Island (MAL) is the last Delta station and represents the Delta output to the Bay. The colors represent the scenarios. The $y$-axis limits are different for the different stations to highlight the impact of the input change. For example, Mokelumne (MOK) cumulative suspended sediment discharge is one order of magnitude lower than Freeport (FPT)
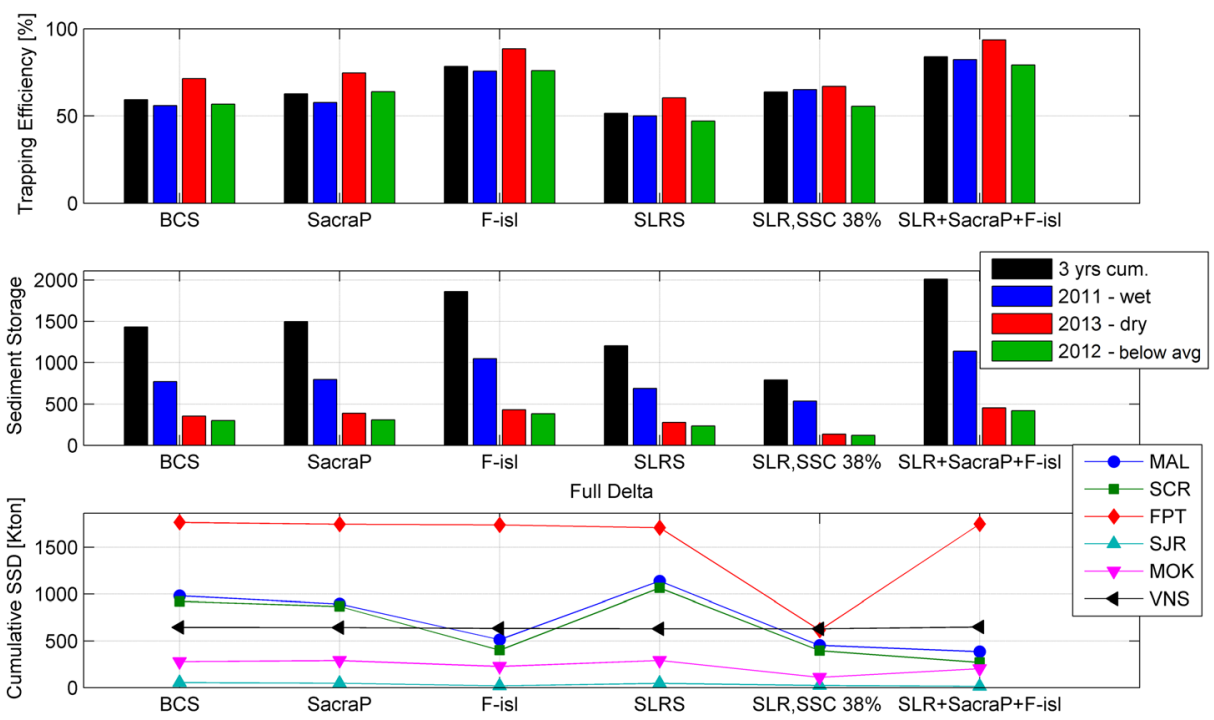

Fig. 5 Trapping efficiency $(\Psi)$ (a) and sediment storage (b), for each scenario on the $x$-axis, for the entire 3 years (black) and for each year, wet (blue), dry (red), and below normal (green). c Cumulative SSD towards the Bay for the 3 years simulated, for each Delta station, for each scenario 
Fig. 6 Base-case exceedance map of SSC higher than $35 \mathrm{mg} \mathrm{L}^{-1}$. The color lines show the $10 \%$ exceedance for each scenario. Landward of the line (to the right) the suspended sediment concentration is higher than $35 \mathrm{mg} \mathrm{L}^{-1}$ during more than $10 \%$ of the time and seaward of the line (to the left) during less than $10 \%$ of the time

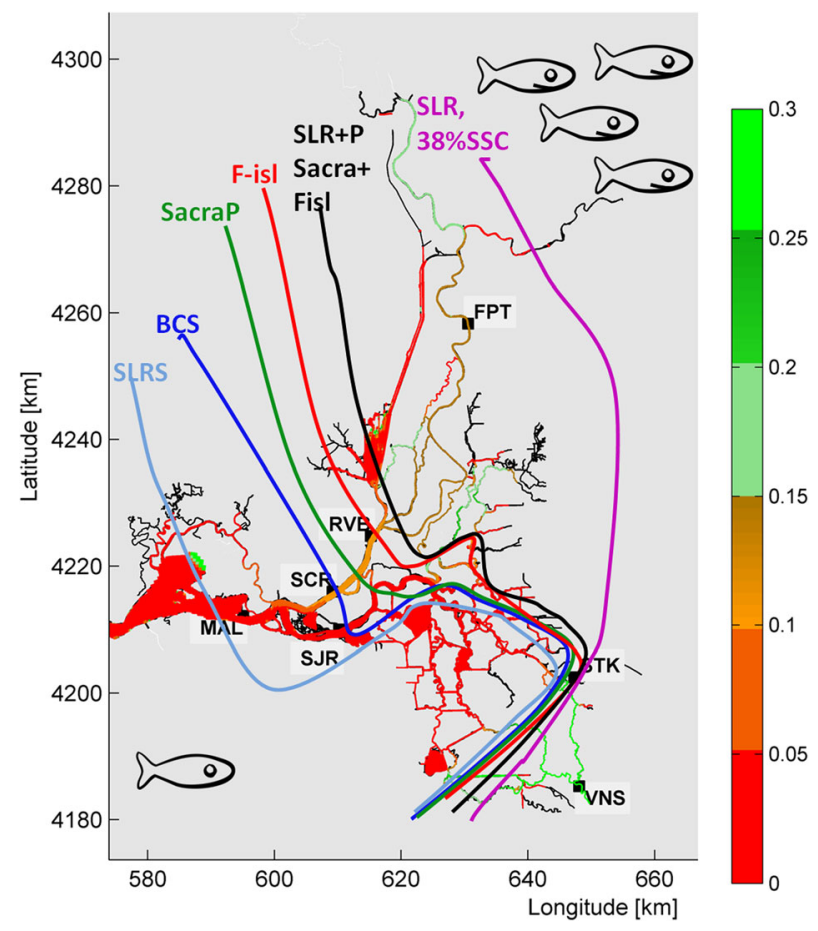

Water pumping has a large impact on the circulation pattern. In the Delta, the shift of pumping from the South to the North Delta had a large effect in the South Delta. The results show the South pumps attracting San Joaquin River water, but the shift to the North allows San Joaquin River water to flow through the Eastern Delta. The river discharge locally increases the water level, and the higher water column decreases bottom friction allowing further penetration of the tidal wave and increasing tidal amplitudes at Stockton (Fig. 3). This results in larger sediment flux in the San Joaquin River branch in the Delta. During peak flow, the change in pumping induces recirculation from the North to Central Delta and shifts the 35-mg$\mathrm{L}^{-1}$ isoline $\sim 5 \mathrm{~km}$ landwards (Fig. 6).

\subsubsection{Sediment dynamics}

Despite the small difference in net water discharge, the combination with the changes in mean water level and tidal propagation leads to a significant impact on suspended sediment discharge (Fig. 4). The SLR scenario increases suspended sediment discharge in the entire Delta, since it enhances tidal action keeping sediment in suspension (Fig. 1), while for the flooded island, and the SLR scenarios, SLR with reduction of sediment input decrease suspended sediment discharge by about one-third. The flooded island scenario has the most impact on the $\Psi$, increasing it by $15 \%$, while in the SLR scenario, $\Psi$ decreases by $10 \%$ (Fig. 5). Flooded islands are the primary sedimentation areas due to the low flow velocities. Further island breaching will probably result in an even higher $\Psi$. An additional scenario which considered flooded islands but not wind-waves was performed to evaluate the importance of winds. In that case, the flooded island trapped $10 \%$ more sediment than if wind-waves were considered. 
The BDCP project calls for a sedimentation basin before pumping the water southward, so we considered that the sediment trapped by the pumps stays in the Delta increasing $\Psi$ on average $5 \%$ compared to the base-case.

The decrease of sediment input from watershed causes the most extreme change in sediment dynamics (Fig. 5b). The decrease in sediment input leads to a sharp decrease in the SSC distribution and sediment deposition in the entire North and Central Delta (Fig. 4). However, the decrease in sediment input has a minor effect in $\Psi$ (Fig. 5). This behavior is observed in historical observations comparing wet and dry years (Erikson et al. 2013; Wright and Schoellhamer 2004).

Apart from the seasonal cycle of wet and dry seasons, the Delta experiences inter-annual cycles of high and low river discharge. In dry and below average years, the amount of sediment deposited in the Delta decreases from $\sim 1500$ (wet) to $\sim 550 \mathrm{kt} \mathrm{year}^{-1}$, and the suspended sediment discharge in San Joaquin River area is virtually zero $\left(2 \mathrm{kt} \mathrm{year}^{-1}\right)$ (Fig. 5). In those years, the influence of SLR, the changing in pumping operation, and decrease of SSC input can lead to cumulative suspended sediment discharge away from the Bay in the Central Delta (Fig. 4).

Though in the dry year sediment deposition in the Delta is almost half of the wet year deposition (Fig. 5b), $\Psi$ is on average 10\% larger due to the lower velocities, the shear stress is lower and the sediment has a longer time to deposit (Fig. 5c). This behavior is observed in all the scenarios.

\section{Discussion}

\subsection{Mitigating impacts}

The current study shows that a process-based model validated against in situ observations can be used to assess the impact of abrupt disasters, direct human impact, and climate change. The latter scenario, obviously, has the longest timescale as the increase in sea level will occur over centuries while an earthquake resulting in levee failure and island flooding takes place in seconds.

A key drawback of the current model is that it does not take into account bed level changes. The calculated positive trapping efficiency suggests that Delta bed levels will accrete. This will have an effect on future trapping efficiencies implying that modeled trapping efficiencies will probably be lower when time scales longer than a few years are considered. The modeled trapping efficiencies in this study should be considered a maximum; lower values should be used for analyses over long time scales.

Our modeling effort shows that direct human impact on sediment dynamics can be significant. This can lead to unwanted developments like the shift in the pumping location decreasing SSC levels in the Central Delta, as is observed in the SSC at SJR (Fig. 6). The decrease in SSC in the Central Delta can affect endemic species survival, such as the Delta smelt (Brown et al. 2013), and may have an impact on marsh restoration projects. Mitigation measures may range, for example, from sediment releases from reservoirs to salt marsh restoration projects or levee construction/reorientation works, and can serve as sustainable water resources management. SLR impacts are smaller compared to the direct human impacts. The impacts have a long-term aspect giving time to plan for adaptation to minimize negative impacts. Natural disasters leading to major structure failure is catastrophic for the system dynamics and leaves almost no room for mitigation or adaptation. 
The model formulations related to hydrodynamics and sediment characteristics are complex. However, despite this complexity, the required model calibration efforts were limited and had limited uncertainty (Achete et al. 2015). This suggests that the model sufficiently described the physical processes to generate a trustworthy prediction of governing sediment dynamics. In addition, the model forcings and the data required to describe those forcings are quite straightforward (a limited number of boundary locations and conditions). This suggests that similar studies can be carried out in data-scarce environments, provided that boundary conditions and initial conditions (bathymetry) are known. In addition, our numerical, processbased approach allows for multiple runs to generate statistical confidence for uncertain model input parameters.

\subsection{Ecological impact}

\subsubsection{Delta smelt}

The Delta maintains important ecosystems and habitat conditions. The model results can be processed to explore the impact on habitat conditions of various species. As an example, the Delta smelt is an important endemic fish that needs specific conditions of salinity, temperature, food availability, and turbidity levels (higher than $18 \mathrm{ntu}$ or $35 \mathrm{mg} \mathrm{L}^{-1}$ ) to survive (Brown et al. 2013, 2016).

To compare the scenarios in terms of turbidity, we evaluated the time percentage of exceeding $35 \mathrm{mg} \mathrm{L}^{-1}$. Landward (eastward) of the isoline (Fig. 6), SSC exceeds $35 \mathrm{mg} \mathrm{L}^{-1}$ for more than $10 \%$ of the time during the 3 -year simulation. This means that habitat conditions are favorable for Delta smelt during more than $10 \%$ of the time while seawards (westwards) of the $10 \%$ isoline the conditions are favorable for less than $10 \%$ of the simulation time. The South Delta turbidity conditions are only affected by the different scenarios to a limited degree, mainly because the sediment dynamics there are governed by the San Joaquin River dynamics (Achete et al. 2015). The Central Delta is the most affected area. The decrease of sediment input (SLR with reduction of sediment input) is the scenario that most affects the habitat conditions followed by the flooded islands and pumping scenarios. All of these scenarios shift the $10 \%$ isoline northward and eastward. In contrast, SLR improves conditions for the Delta smelt because sediment stays longer in the water column keeping turbidity higher for a longer period of time.

This analysis shows the potential of applying process-based modeling techniques in ecosystem studies. We also recognize that the analysis is rudimentary and would require more knowledge on turbidity requirements (e.g., are there seasonal fluctuations?) and should include other conditions such as vegetation presence, salinity, and water temperature.

\subsubsection{Marsh restoration}

Marshes are valuable ecosystems for fauna and flora as well as for coastal protection. Marshland growth and survival depends on organic matter supply by the marsh vegetation itself, and on sediment supply by rivers (Kirwan et al. 2016). Restoration projects become an option to mitigate possible impacts of SLR and preserve biodiversity. For restoration projects where vegetation is absent, sediment is the key factor to success. Salt marsh restoration, for example, by flooding islands will have different effects on the system. It can increase the tidal prism and act as a sediment sink depending on the level of restoration. In addition, restoration will reduce prevailing SSC levels since sediment can deposit in the salt marsh. 
For marshland development, the most favorable scenarios are the ones increasing trapping efficiency, like the flooded island scenario. In contrast, a decrease of sediment input is the least favorable scenario for marsh restoration. Highly engineered estuaries have most of their banks diked. These structures do not leave much space for an increase in tidal prism. However, creating accommodation via marsh restoration can benefit from the SLR scenario keeping sediment in suspension during longer period.

\section{Conclusions}

Process-based models provide a promising tool to assess the impacts of SLR and direct human impacts in estuaries worldwide with only limited information (forcing at the boundaries, geometry, and bathymetry). Our validated model provides a useful tool to address anticipated changes in the Delta as the result of human interventions and SLR. Model results show clear impacts of different scenarios based on detailed process descriptions. The model provides a validated basis for future studies on ecosystem impacts in terms of possible changes and mitigation actions. The scenarios presented here can now be used as input for ecological models such as phytoplankton, clams, and fishes, enabling assessment of the possible impacts.

Dry year conditions and the Central Delta are more vulnerable, while wet year conditions and North Delta are more resilient. Regardless of the uncertainty related to the definition of the scenarios, they give indications of the potential impacts allowing for possible remediation. This study and findings for the Sacramento-San Joaquin Delta indicate possible impacts affecting estuarine ecosystem functioning. It shows that conditions will change as the result of human intervention, but it also opens up possibilities for addressing and mitigating impacts in a sustainable manner through management.

Structural failure can change hydrodynamics by increasing the tidal prism, generating secondary circulations and accommodation. In the Delta, the increase in accommodation and decrease in velocities increases trapping efficiency by $15 \%$. The decrease in sediment input is the factor that contributes most to turbidity level variations as reflected in both sediment deposition and suspended sediment concentration distribution. Engineer structures do not leave much space for increase of tidal prism due to SLR, which in combination with increasing velocities and deeper water column leads to higher export of sediment. Changes in tidal prism is key for the adaptation of the ecosystem. If under SLR the estuary is highly engineered and has little or no room for increasing tidal prism, then the tendency is for increased sediment export.

Direct human impacts may be more easily mitigated than SLR because, unlike SLR that effects large areas and is expected to continue for a long time requiring persistent and potentially increasing mitigation measures, they typically are spatially more limited and do not persist through time. Adapting to the changes in dynamics resulting from SLR may be a more effective strategy.

Impacts from the scenarios we explored - a direct human impact (shift in water pumping location), climate change (SLR and SSC decrease) and abrupt disasters (island flooding, possibly as the results of an earthquake) - can improve or deteriorate the current habitat and change system dynamics. An unanswered question is how much we should manage estuaries in order to fit our needs. This modeling exercise contributes to a better assessment of possible future impacts of climate change and human disturbance on estuarine systems. 
Acknowledgements The research is part of the US Geological Survey CASCaDE climate change project (CASCaDE contribution 64). The authors acknowledge the US Geological Survey Priority Ecosystem Studies and CALFED for making this research financially possible and the Delta Sediment Project for the data. This research was also partially funded by the Brazilian Government via Capes agency. The model applied in this work will be freely available from http://www.D-Flow-baydelta.org/. Rose Martyr (USGS) provided a helpful review of the manuscript before submission. Lisa Lucas (USGS) and Noah Knowles (USGS) supplied valuable input concerning scenario definitions.

Open Access This article is distributed under the terms of the Creative Commons Attribution 4.0 International License (http://creativecommons.org/licenses/by/4.0/), which permits unrestricted use, distribution, and reproduction in any medium, provided you give appropriate credit to the original author(s) and the source, provide a link to the Creative Commons license, and indicate if changes were made.

\section{References}

[NRC] National Research Council (2012) Sea-level rise for the coasts of California, Oregon, and Washingtonpast, present and future. Report of the committee on sea level rise in California, Oregon, and Washington. National Academies Press, Washington, D.C., p 202

Achete FM, van der Wegen M, Roelvink D, Jaffe B (2015) A 2-D process-based model for suspended sediment dynamics: a first step towards ecological modeling. Hydrol Earth Syst Sci 19:2837-2857. doi:10.5194/hess19-2837-2015

Ariathurai R, Arulanandan K (1978) Erosion rates of cohesive soils. J Hydraul Div 104:5

Barnard PL, Schoellhamer DH, Jaffe BE, McKee LJ (2013) Sediment transport in the San Francisco Bay coastal system: an overview. Mar Geol 345:3-17

Beagle J, Downs PW, Grossinger RM, Orr BK, Salomon M (2015) Historical ecology and landscape change in the Sacramento-San Joaquin Delta. HydroLink [Internet]. 1. https://www.iahr.org/site/cms/newsarticle. asp? chapter $=96 \&$ nid $=643$

Borrego J, Morales JA, Pendón JG (1993) Holocene filling of an estuarine lagoon along the mesotidal coast of Huelva: the Piedras River mouth, southwestern Spain. J Coast Res:242-254

Brooks BA, Bawden G, Manjunath D, Werner C, Knowles N, Foster J et al (2012) Contemporaneous subsidence and levee overtopping potential, Sacramento-San Joaquin Delta, California. San Francisco Estuary and Watershed Science 10(1). Retrieved from: http://escholarship.org/uc/item/15g1b9tm

Brown LR et al (2013) Implications for future survival of delta smelt from four climate change scenarios for the Sacramento-San Joaquin Delta, California. Estuar Coasts 36:754-774. doi:10.1007/s12237-013-9585-4

Brown LR, Komoroske LM, Wagner RW, Morgan-King T, May JT, Connon RE, Fangue NA (2016) Coupled downscaled climate models and ecophysiological metrics forecast habitat compression for an endangered estuarine fish. PLoS One 11:e0146724. doi:10.1371/journal.pone.0146724

Delta Atlas (1995) Sacramento-San Joaquin Delta atlas vol 7. DWR - Department of Water Resources, Sacramento

Deltares. D-Flow Flexible Mesh, Technical Reference Manual [Internet]. Delft: Deltares; 2014. Available from: http://content.oss.deltares.nl/delft3d/manuals/D-Flow_FM_Technical_Reference.pdf

Dettinger M, Anderson J, Anderson M, Brown L, Cayan D., Maurer E. 2016 Climate change and the Delta. San Franc Estuary Watershed Sci, 26 p. doi:10.15447/sfews.2016v14iss3art4

Erikson LH, Wright SA, Elias E, Hanes DM, Schoellhamer DH, Largier J (2013) The use of modeling and suspended sediment concentration measurements for quantifying net suspended sediment transport through a large tidally dominated inlet. Mar Geol. doi:10.1016/j.margeo.2013.06.001

Fagherazzi S et al (2012) Numerical models of salt marsh evolution: ecological, geomorphic, and climatic factors. Rev Geophys 50:RG1002. doi:10.1029/2011 $\operatorname{rg} 000359$

Ganju NK, Schoellhamer DH (2006) Annual sediment flux estimates in a tidal strait using surrogate measurements. Estuar Coast Shelf Sci 69:165-178. doi:10.1016/j.ecss.2006.04.008

Guillén J, Palanques A (1997) A historical perspective of the morphological evolution in the lower Ebro river. Environ Geol 30:174-180

Hestir EL, Schoellhamer DH, Morgan-King T, Ustin SL (2013) A step decrease in sediment concentration in a highly modified tidal river delta following the 1983 El Nino floods. Mar Geol 345:304-313. doi:10.1016/j. margeo.2013.05.008

Jaffe BE, Smith RE, Foxgrover AC (2007) Anthropogenic influence on sedimentation and intertidal mudflat change in San Pablo Bay, California: 1856-1983. Estuar Coast Shelf Sci 73:175-187. doi:10.1016/j. ecss.2007.02.017 
Jassby AD, Cloern JE, Powell MA (1993) Organic carbon sources and sinks in San Francisco Bay: variability induced by river flow. Mar Ecol Prog Ser 95:15

Kernkamp HWJ, Van Dam A, Stelling GS, De Goede ED (2010) Efficient scheme for the shallow water equations on unstructured grids with application to the Continental Shelf. In: Ocean Dynamics, vol Special Issue JONSMOD p 29

Kimmerer W (2004) Open water processes of the San Francisco estuary: from physical forcing to biological responses. San Francisco Estuary and Watershed Science 2(1). Retrieved from: http://escholarship. org/uc/item/9bp499mv

Kirwan L, Temmerman S, Skeehan EE, Guntenspergen GR, Fagherazzi S (2016) Overestimation of marsh vulnerability to sea level rise. Nature Clim Change 6(3):253-260. doi:10.1038/nclimate2909

Knowles N, Cayan DR (2002) Potential effects of global warming on the Sacramento/San Joaquin watershed and the San Francisco estuary. Geophys Res Lett 29:38-31-38-34

Krone RB (1962) Flume studies of the transport of sediment in estuarial shoaling processes. University of California, Berkeley

Ludwig FL, Sinton D (2000) Evaluating an objective wind analysis technique with a long record of routinely collected data. J Appl Meteorol 39:335-348

van Maren DS, van Kessel T, Cronin K, Sittoni L (2015) The impact of channel deepening and dredging on estuarine sediment concentration. Cont Shelf Res 95:1-14. doi:10.1016/j.csr.2014.12.010

Marineau M, Wright S (2014) Human alterations of channel characteristics in the delta and effects on hydrodynamics and sediment transport. In: Sediment Dynamics from the Summit to the Sea (Proceedings of a symposium held in New Orleans, Louisiana, USA, 11-14 December 2014) (IAHS Publ. 367, 2014), pp. $11-14$

McKee LJ, Ganju NK, Schoellhamer DH (2006) Estimates of suspended sediment entering San Francisco Bay from the Sacramento and San Joaquin Delta, San Francisco Bay, California. J Hydrol 323:335-352. doi:10.1016/j.jhydrol.2005.09.006

McKee LJ, Lewicki M, Schoellhamer DH, Ganju NK (2013) Comparison of sediment supply to San Francisco Bay from watersheds draining the Bay Area and the Central Valley of California. Mar Geol 345:47-62. doi:10.1016/j.margeo.2013.03.003

Reed D (2002) Sea-level rise and coastal marsh sustainability: geological and ecological factors in the Mississippi delta plain. Geomorphology 48:10

Roy PS (1994) Holocene estuary evolution: stratigraphic studies from southeastern Australia. In: Dalrymple R, Boyd R, Zaiklin BA (eds) Incised valley systems: origin and sedimentary sequences, SEPM Special Publication S1, 241-263

Scavia D et al. (2002) Climate change impacts on U.S. Coastal and Marine Ecosystems Estuaries 25:149-164. doi:10.1007/bf02691304

Schoellhamer D (2011) Sudden clearing of estuarine waters upon crossing the threshold from transport to supply regulation of sediment transport as an erodible sediment pool is depleted: San Francisco Bay, 1999. Estuar Coasts 34:885-899. doi:10.1007/s12237-011-9382-x

Schoellhamer DH, Wright SA, Drexler JZ (2013) Adjustment of the San Francisco estuary and watershed to decreasing sediment supply in the 20th century. Mar Geol 345:63-71. doi:10.1016/j.margeo.2013.04.007

Syvitski JPM, Vörösmarty CJ, Kettner AJ, Green P (2005) Impact of humans on the flux of terrestrial sediment to the global coastal ocean. Science 308:376-380. doi:10.1126/science.1109454

Walling DE, Fang D (2003) Recent trends in the suspended sediment loads of the world's rivers. Glob Planet Chang 39:111-126. doi:10.1016/S0921-8181(03)00020-1

Wang ZB, Van Maren DS, Ding PX, Yang SL, Van Prooijen BC, De Vet PLM, Winterwerp JC, De Vriend HJ, Stive MJF, He Q (2015) Human impacts on morphodynamic thresholds in estuarine systems. Cont Shelf Res 111:174-183

Warrick JA (2014) Trend analyses with river sediment rating curves. Hydrol Process 29:936-949 (2015) (wileyonlinelibrary.com). doi:10.1002/hyp.10198

Whitney M, Jia Y, McManus P, Kunz C (2014) Sill effects on physical dynamics in eastern Long Island sound. Ocean Dyn 64:443-458. doi:10.1007/s10236-013-0681-6

Winterwerp J, Wang Z (2013) Man-induced regime shifts in small estuaries_- I: theory. Ocean Dyn 63:12791292. doi:10.1007/s10236-013-0662-9

Wright SA, Schoellhamer DH (2004) Trends in the Sediment Yield of the Sacramento River, California, 19572001. San Francisco Estuary and Watershed Science 2(2). Retrieved from: http://escholarship. org/uc/item/891144f4

Wright SA, Schoellhamer DH (2005) Estimating sediment budgets at the interface between rivers and estuaries with application to the Sacramento-San Joaquin River Delta. Water Resour Res 41:1-17. doi:10.1029/2004 wr003753 